\title{
Changes in FKBP5 expression and memory functions during cognitive-behavioral therapy in posttraumatic stress disorder: A preliminary study
}

\author{
Csilla Szabóa,b ${ }^{a}$ Oguz Kelemen ${ }^{c}$, Szabolcs Kéri ${ }^{\mathrm{a}, \mathrm{b}, \mathrm{d}, *}$ \\ a Department of Physiology, Faculty of Medicine, University of Szeged, Szeged, Hungary \\ ${ }^{\mathrm{b}}$ Nyírö Gyula Hospital-National Institute of Psychiatry and Addictions, Budapest, Hungary \\ c Bács-Kiskun County Hospital, Psychiatry Center, Kecskemét, Hungary \\ d Budapest University of Technology and Economics, Department of Cognitive Science, Budapest, Hungary
}

\section{H I G H L I G H T S}

- Patients with PTSD show deficits in delayed recall and paired associates learning.

- Memory deficits are ameliorated during CBT.

- Memory improvement correlates with the expression of blood FKBP5 mRNA.

\section{A R T I C L E I N F O}

\section{Article history:}

Received 21 February 2014

Received in revised form 13 March 2014

Accepted 26 March 2014

\section{Keywords:}

Posttraumatic stress disorder

Memory

Cognitive behavioral therapy

FKBP5

\begin{abstract}
A B S T R A C T
Posttraumatic stress disorder (PTSD) is characterized by hyperarousal, flashbacks, avoidance, and memory dysfunctions. Although psychotherapy improves the clinical symptoms, its effect on memory has not been explored. In addition, there is no information about gene expression changes related to hippocampal functions. We assessed PTSD patients $(n=20)$ using the Wechsler Memory Scale-Revised (WAIS-R) and a paired associates learning (PAL) test, as well as changes in blood FK506 binding protein (FKBP5) mRNA expression before and after cognitive behavioral therapy (CBT). Results revealed that before CBT PTSD patients were impaired on WAIS-R delayed recall, attention/concentration, and PAL compared with trauma-exposed control subjects $(n=20)$. These memory dysfunctions showed a significant improvement after CBT. Better performance on the PAL test correlated with enhanced blood FKBP5 mRNA expression. These results suggest that elevated FKBP5 expression during CBT is related to improved associative memory linked to the hippocampal formation.
\end{abstract}

(C) 2014 Elsevier Ireland Ltd. All rights reserved.

\section{Introduction}

Posttraumatic disorder (PTSD) is characterized by significant avoidance behavior, hyperarousal, and intrusive mental contents including thoughts, flashback images, and nightmares related to the traumatic event [1]. The pathophysiology of PTSD is unknown although a role of the overactive hypothalamic-pituitary stress axis has been suggested as one of the most important putative pathophysiological mechanism [2]. FKBP5 (FK506 binding protein) may be a remarkable hub in complex molecular networks regulating the

\footnotetext{
* Corresponding author at: University of Szeged, Department of Physiology, Dóm sq. 10, H6720 Szeged, Hungary. Tel.: +36 20448 3530; fax: +36 62545842.

E-mail addresses: keri.szabolcs.gyula@med.u-szeged.hu, szkeri2000@yahoo.com (S. Kéri).
}

effect of the stress hormone cortisol, and evidence strongly suggests its role in the pathogenesis of PTSD [3-7]. FKBP5 binds to the cortisol receptor and reduces its affinity and nuclear translocation [8]. Recently, we found that symptomatic improvement during cognitive-behavioral therapy (CBT) in PTSD was associated with an increased expression of FKBP5 and an expansion of hippocampal volume [9], which exhibits a reduced size in patients with PTSD who display active clinical symptoms [10-12]. We also demonstrated a significant positive correlation between changes in hippocampal size and FKBP5 expression during CBT [9]. One possible explanation is that enhanced FKBP5 expression mitigates the detrimental effect of cortisol and consequently protects the hippocampal formation.

However, the functional consequences of larger hippocampi regarding impaired learning and memory in PTSD are unknown. The present study was designed to clarify this issue. We measured memory functions and FKBP5 expression in PTSD before and after 
CBT. We hypothesized that patients with PTSD would show better memory functions in parallel with enhanced blood FKBP5 mRNA expression after CBT.

\section{Materials and methods}

\subsection{Participants}

We assessed 20 newly diagnosed patients with PTSD and 20 trauma-exposed non-PTSD volunteers at the early trauma intervention center (National Psychiatry Center, Budapest, Hungary). The details of the recruitment process have been described in details in our previous report [9]. The patients in the present study comprised an independent sample and did not participate in our previous study. None of them received psychotropic drugs. Participants received the Structured Clinical Interview for DSMIV axis I disorders (SCID-CV) [13], the Trauma and Life Events Self-report Inventory (TLESI) [14], the Clinician-Administered PTSD Scale (CAPS) [15], and the Hamilton Depression Rating Scale (HAMD) [16]. All scales were administered by trained and regularly supervised clinicians who were blind to the aim of the study. Exclusion criteria included history of psychiatric or neurological disorders. The control group included trauma-exposed individuals without PTSD or other Axis I disorders. The demographic and clinical data are presented in Table 1 . The study was carried out in accordance with the Declaration of Helsinki and was approved by the local ethics board. All participants gave written informed consent.

\subsection{Procedure and $C B T$}

At the first assessment, patients with PTSD and traumaexposed controls underwent memory assessment and blood sample drawing. After this assessment, patients with PTSD received trauma-based CBT according to the protocol of Marks et al. [17] (for Hungarian adaptation, see [18]). CBT helps to identify, challenge, and change negative automatic thoughts and maladaptive cognitive schemas. Clinical psychologists or psychiatrists with adequate training and regular supervision administered 12 weekly 1.5 -h sessions. The controls did not participate in any psychological intervention. After the 12-week period, patients with PTSD and controls were re-assessed including memory tests and blood sample drawing.

\subsection{Gene expression}

The method has been described and referred in details in Yehuda et al. [5] and in our previous study [9]. We drew fasting blood samples between 08:00 and 09:00 h. For screening purposes, we used Human Genome U133 Plus 2.0 Array (Affymetrix, Santa Clara, California), which was followed by qPCR for FKBP5 gene expression $[5,9]$. At the second assessment, we performed only qPCR in order to explore its possible changes after CBT. In addition to FKBP5, we analyzed Ribosomal Protein S6 Kinase (RPS6K) (90 kDa; Affy ID: 204633_s_at) RNA as a control molecule. RPS6K has been shown to be significantly decreased in PTSD [5] and does not change during CBT [9]. In this study, only relative gene expression data of FKBP5 and RPS6K are reported.

\subsection{Memory assessment}

The Wechsler Memory Scale-Revised (WMS-R) was used to assess memory functions [19]. The test provides 5 indices based on 13 subtests: verbal, visual and general memory, delayed recall, and attention/concentration. The raw data were converted to agecorrected standard scores according to the test manual [19].

We also administered a paired associates learning (PAL) test, a sensitive measure for hippocampal functions, modified after the Cambridge Neuropsychological Test Automated Battery (CANTAB) [20] and validated in different patients populations (autism and dementias) [21]. Six objects (candies) were hidden in six candy boxes placed in different locations on the computer screen (i-PAN4 MC, Keith \& Koep, Wuppertal, Germany). The objects had different shape and color (circle, triangle, square, diamond, red, green, blue, yellow, pink and brown). The boxes were opened for $3 \mathrm{~s}$ in a randomized order. After this observation period, one of the objects was presented in the middle on the screen. The task was to touch the box where the object was originally hidden. When the participant made a mistake, the boxes were opened again. The dependent measure was the number of errors during the PAL test.

\subsection{Data analysis}

The STATISTICA 11 (StatSoft, Inc., Tulsa) software was used for data analysis. After ensuring that the data showed normal distributions (Kolmogorov-Smirnov tests), we performed analyses of variance (ANOVAs), Student's $t$ tests, and Tukey's Honestly Significant Difference (HSD) tests. Pearson's correlation coefficients were performed to evaluate the relationship between changes in gene

Table 1

Clinical and demographic characteristics of the participants.

\begin{tabular}{|c|c|c|}
\hline & PTSD $(n=20)$ & Trauma-exposed controls $(n=20)$ \\
\hline Age (years) & $42.4(9.6)$ & $44.0(12.8)$ \\
\hline Gender (male/female) & $6 / 14$ & $8 / 12$ \\
\hline Education (years) & $11.8(3.5)$ & $12.2(4.7)$ \\
\hline \multirow[t]{4}{*}{ Type of trauma } & Traffic accidents $(n=7)$ & Traffic accidents $(n=9)$ \\
\hline & Violent crime $(n=8)$ & Violent crime $(n=8)$ \\
\hline & Natural disasters $(n=3)$ & Natural disasters $(n=2)$ \\
\hline & Combat $(n=2)$ & Combat $(n=1)$ \\
\hline Alcohol consumption (drinks/week) & $3.4(6.1)$ & $4.4(7.9)$ \\
\hline Smoking (cigarettes/week) & $5.5(12.3)$ & $4.7(11.2)$ \\
\hline Trauma and Life Events Self-Report Inventory & $5.7(4.8)$ & $4.3(3.7)$ \\
\hline Duration of symptoms (months) & $2.4(3.0)$ & - \\
\hline Time since trauma (months) & $9.6(4.5)$ & $10.4(5.6)$ \\
\hline \multirow[t]{2}{*}{ CAPS $^{*}$} & Before CBT: 65.7 (14.3) & - \\
\hline & After CBT: $50.0(14.8)$ & \\
\hline \multirow[t]{2}{*}{ HAM-D ${ }^{*}$} & Before CBT: 30.1 (11.1) & - \\
\hline & After CBT: $20.0(9.2)$ & \\
\hline
\end{tabular}

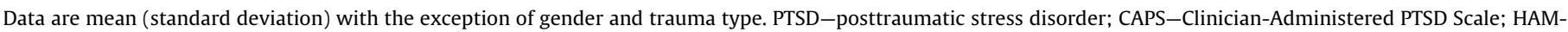
D-Hamilton Depression Rating Scale; CBT-cognitive-behavior therapy. Patients with PTSD and controls did not differ in demographic measures ( $p>0.1$ ).

$p<0.005$ (Student's $t$ test, before vs. after CBT). 
Table 2

Gene expression results.

\begin{tabular}{|c|c|c|c|c|}
\hline & PTSD before CBT $(n=20)$ & PTSD after CBT $(n=20)$ & Controls at baseline $(n=20)$ & Controls at follow-up $(n=20)$ \\
\hline FKBP5 ${ }^{*}$ & $0.75(0.21)$ & $1.06(0.31)$ & $1.10(0.28)$ & $1.12(0.34)$ \\
\hline RPS6K $^{* *}$ & $0.82(0.28)$ & $0.84(0.33)$ & $1.17(0.35)$ & $1.18(0.37)$ \\
\hline
\end{tabular}

Data are mean (standard deviation). PTSD-posttraumatic stress disorder; CBT-cognitive-behavior therapy.

* Controls $>$ PTSD before CBT ( $p<0.01$, Tukey's HSD following ANOVA).

** Controls $>$ PTSD before and after CBT $(p<0.005$, ANOVA).

expression and memory functions. Partial correlations were calculated to control the effect of improvement in the CAPS and HAM-D scales. The threshold of statistical significance was $\alpha<0.05$.

\section{Results}

\subsection{Gene expression}

The ANOVA conducted on blood FKBP5 mRNA expression revealed significant main effects of group (PTSD vs. controls) $\left(F(1,38)=5.27, p<0.05, \eta^{2}=0.12\right.$, observed power: 0.61$)$ and session (before vs. after CBT in PTSD, baseline vs. follow-up in controls receiving no therapy) $\left(F(1,38)=22.39, p<0.001, \eta^{2}=0.37\right.$, observed power: 0.99). The two-way interaction was significant $\left(F(1,38)=9.91, p<0.005, \eta^{2}=0.21\right.$, observed power: 0.87$)$.

At baseline (before CBT), patients with PTSD displayed significantly lower blood FKBP5 mRNA expression compared with the control subjects $(p=0.006)$, which was not detected after CBT $(p=0.89)$. Patients with PTSD had significantly increased FKBP5 expression during CBT $(p<0.001)$, whereas the control subjects showed a good test-retest consistency $(p=0.7)$. The data are depicted in Table 2 .

The ANOVA investigating blood RPS6K mRNA expression indicated a significant main effect of group $(F(1,38)=11.27, p<0.005$, $\eta^{2}=0.28$, observed power: 0.91 ), but the effect of session and the interaction were not significant $(p>0.3)$ (Table 2$)$.

\section{2. $P A L$}

The ANOVA conducted on the number of errors revealed significant main effects of group (PTSD vs. controls) $(F(1,38)=6.01$, $p<0.05, \eta^{2}=0.14$, observed power: 0.66 ) and session (before vs. after CBT in PTSD, baseline vs. follow-up in controls receiving no therapy) $\left(F(1,38)=11.88, p<0.005, \eta^{2}=0.24\right.$, observed power: $0.92)$. The two-way interaction was also significant $(F(1,38)=10.12$, $p<0.005, \eta^{2}=0.21$, observed power: 0.88 ).

Tukey's HSD tests indicated that before CBT patients with PTSD had more errors as compared with the performance of the control subjects $(p=0.005)$, but after CBT this difference in PAL performance disappeared $(p=0.7)$. Patients showed a marked improvement during CBT $(p<0.001)$, whereas the performance of the control subjects was stable $(p=0.9)$ (Table 3$)$.

\subsection{WAIS-R}

We found a significant main effect of group in the case of attention/concentration $\left(F(1,38)=6.17, p<0.05, \eta^{2}=0.14\right.$, observed power: 0.68$)$, a main effect of session $(F(1,38)=10.50, p<0.005$ $\eta^{2}=0.22$, observed power: 0.88 ), and a two-way interaction $\left(F(1,38)=7.47, p<0.05, \eta^{2}=0.16\right.$, observed power: 0.76$)$. Before CBT, patients performed poorly relative to controls $(p<0.05)$, but after CBT their performance was comparable to that of the control subjects $(p=0.4)$. The improvement during CBT was significant $(p<0.005)$ (Table 3).

The other significant WMS-R index was delayed memory (main effect of group: $F(1,38)=4.17, p<0.05, \eta^{2}=0.10$, observed power: 0.51 ; main effect of session: $\left(F(1,38)=5.71, p<0.05, \eta^{2}=0.13\right.$, observed power: 0.64 ; interaction: $F(1,38)=4.47, p<0.05, \eta^{2}=0.11$, observed power: 0.54$)$. Before CBT, patients were impaired relative to controls $(p<0.05)$, but after CBT there was no between-group difference $(p=0.9)$. As expected, patients showed a significant improvement during CBT $(p<0.05)$, whereas controls did not do so $(p=0.9)$ (Table 3$)$.

In the case of visual, verbal, and general memory, there were no significant main effects or interactions $(F<1, p>0.1)$ (Table 3$)$.

\subsection{Correlations}

We calculated three hypothesis-driven correlation coefficients between changes in FKBP5 expression and changes in PAL, attention/concentration, and delayed recall (change: values after CBT-values before CBT). There was a significant relationship between changes in blood FKBP5 MRNA and PAL $(r=-0.53$, $p<0.05)$. The other two correlations between FKBP5 and WMS$\mathrm{R}$ indices were not significant $(-0.1<r<0.1, p>0.1)$. When the changes in CAPS scores were included in a partial correlation analysis, the results remained significant between FKBP5 and PAL $(r=-0.48, p<0.05)$, similarly to the case when changes in HAM-D scores were controlled $(r=-0.53, p<0.05)$.

\section{Discussion}

We found robustly increased blood FKBP5 mRNA expression in PTSD after CBT, which is a replication of our previous findings [9] in an independent sample. This is not a general enhancement of gene expression because RPS6K, a widespread factor playing a key role in the activity of ribosomes, remained unchanged [5,9].

Table 3

Performance on the WMS-R and PAL tests.

\begin{tabular}{|c|c|c|c|c|}
\hline & PTSD before CBT $(n=20)$ & PTSD after CBT $(n=20)$ & Controls at baseline $(n=20)$ & Controls at follow-up $(n=20)$ \\
\hline Attention/concentration ${ }^{*}$ & $88.4(10.5)$ & $94.3(9.5)$ & $98.5(9.8)$ & $99.0(10.1)$ \\
\hline Delayed recall & $86.9(11.6)$ & $95.4(12.1)$ & $97.7(9.1)$ & $98.3(14.6)$ \\
\hline Verbal memory & $94.3(12.7)$ & $96.9(10.2)$ & $96.0(11.5)$ & $96.3(11.3)$ \\
\hline Visual memory & $91.5(13.8)$ & $93.0(12.7)$ & $92.0(9.5)$ & $91.7(10.0)$ \\
\hline General memory & $89.9(14.0)$ & $91.3(13.9)$ & $95.5(15.4)$ & $92.6(14.9)$ \\
\hline $\mathrm{PAL}^{*}$ & $13.7(5.9)$ & $9.9(4.4)$ & $8.7(3.8)$ & $8.5(3.9)$ \\
\hline
\end{tabular}

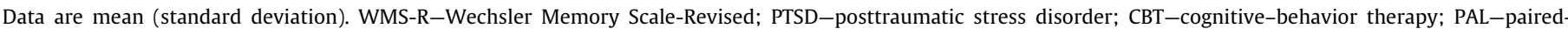
associates learning.

* Patients with PTSD were impaired before CBT $(p<0.05$, Tukey's HSD test following ANOVA), but not after CBT. 
Before CBT, patients with PTSD showed impaired WMS-R delayed recall, attention/concentration, and PAL relative to the traumaexposed controls. The memory deficit in PTSD was not generalized. Memory dysfunctions in PTSD showed a remarkable amelioration after CBT, and PAL improvement was associated increased blood FKBP5 mRNA expression. Although numerous studies have reported impaired declarative memory in PTSD [22-26], this is the first study showing that CBT may boost memory. The fact that PAL was associated with FKBP5 expression is not surprising, assuming that both are closely related to the hippocampus: PAL is a prototypical test for hippocampal functioning [20] and enhanced FKBP5 may be associated with the regeneration of hippocampal networks in PTSD [9]. In this respect, the present study has limitations because we were not able to measure hippocampal volume or activation in this sample. Moreover, conventional neuropsychological tests of memory fail to show a significant correlation with hippocampal volume in PTSD [27], whereas tests more specifically related to hippocampal functions (e.g., associative learning and acquired equivalence) may do so [28]. This hypothesis is supported by our results revealing a relationship between PAL and FKBP5 but not between WMS-R and FKBP5.

Another limitation is that the analysis was confined to the expression of a single hypothesis-driven gene (FKBP5) with a known role in PTSD and a gene displaying significant alteration in PTSD without clear biological relevance (RPS6K) [5,9]. However, we intended to avoid multiple comparisons because of the small sample size, and FKBP5 is one of the most promising candidates as a clinically relevant factor in the regulation of the hypothalamicpituitary stress axis and cortisol [8]. Similarly, we did not examine how altered gene expression and memory functions were related to large-scale neuronal networks implicated in the pathogenesis of PTDS. Finally, the results must be replicated in more severely affected and chronic patients. We were not able to measure FKBP5 protein, which is a critical issue because mRNA levels do not always correspond with protein levels. A recent study provided evidence for a parallel decrease of FKBP5 mRNA and protein in the amygdala of suicide victims [29], but this relationship remains to be explored in the peripheral blood.

FKBP5 is a regulator protein of the cortisol receptor, and abnormal cortisol secretion is linked to hippocampal atrophy and poor declarative memory [30,31]. Therefore, it is reasonable to assume that boosted FKBP5 expression had a causal role in the normalization of hippocampal function and memory improvement. Enhanced neurogenesis, increased neuronal size, and enrichment of dendritic arborization are the putative mechanisms of volume expansion $[30,31]$. However, little is known about the relationship between blood FKBP5 and brain structure and function. We showed a positive relationship between blood FKBP5 mRNA expression and hippocampal volume in PTSD [9]. Others demonstrated similar correlations with different circulating mRNAs of glucocorticoid receptor-related factors (GILZ and SGK-1) in major depressive disorder [32]. Although increasing evidence suggests that genetic variations of the FKBP5 gene have an impact on the structure and function of the hippocampus and amygdala e.g., [33-35], future studies are needed to evaluate the relationships between circulating factors (mRNA and protein) and brain structure and function. The results of the present study must be replicated in a larger sample.

\section{Conclusion}

CBT is accompanied by improved memory in PTSD, which cannot be explained by the amelioration of clinical symptoms. Increased expression of FKBP5, a key intracellular regulator of stress response and hippocampal function, may be critical in cognitive changes. These results provide a new insight into the relationship among clinical, molecular, and cognitive features of PTSD.

\section{Acknowledgments}

This research was supported by the European Union and the State of Hungary, co-financed by the European Social Fund in the framework of TÁMOP-4.2.4.A/2-11/1-2012-0001 'National Excellence Program'.

\section{References}

[1] American Psychiatric Association, The Diagnosis and Statistical Manual of Mental Disorders, fourth ed., American Psychiatric Association, Washnigton, DC, 1994.

[2] R. Yehuda, Status of glucocorticoid alterations in post-traumatic stress disorder, Ann. N.Y. Acad. Sci. 1179 (2009) 56-69

[3] C. Touma, N.C. Gassen, L. Herrmann, J. Cheung-Flynn, D.R. Büll, I.A. Ionescu, J.M. Heinzmann, A. Knapman, A. Siebertz, A.M. Depping, J. Hartmann, F. Hausch, M.V. Schmidt, F. Holsboer, M. Ising, M.B. Cox, U. Schmidt, T. Rein, FK506 binding protein 5 shapes stress responsiveness: modulation of neuroendocrine reactivity and coping behavior, Biol. Psychiatry 70 (2011) 928-936.

[4] R.H. Segman, N. Shefi, T. Goltser-Dubner, N. Friedman, N. Kaminski, A.Y. Shalev, Peripheral blood mononuclear cell gene expression profiles identify emergent post-raumatic stress disorder among trauma survivors, Mol. Psychiatry $10(500-513)(2005) 425$

[5] R. Yehuda, G. Cai, J.A. Golier, C. Sarapas, S. Galea, M. Ising, T. Rein, J. Schmeidler B. Müller-Myhsok, F. Holsboer, J.D. Buxbaum, Gene expression patterns associated with posttraumatic stress disorder following exposure to the World Trade Center attacks, Biol. Psychiatry 66 (2009) 708-711.

[6] C. Sarapas, G. Cai, L.M. Bierer, J.A. Golier, S. Galea, M. Ising, T. Rein, J. Schmeidler, B. Müller-Myhsok, M. Uhr, F. Holsboer, J.D. Buxbaum, R. Yehuda, Genetic markers for PTSD risk and resilience among survivors of the World Trade Center attacks, Dis. Markers 30 (2011) 101-110.

[7] M.van Zuiden, E. Geuze, H.L. Willemen, E. Vermetten, M. Maas, K. Amarouchi, A Kavelaars, C.J. Heijnen, Glucocorticoid receptor pathway components predict posttraumatic stress disorder symptom development: a prospective study, Biol. Psychiatry 71 (2012) 309-316.

[8] E.B. Binder, The role of FKBP5, a co-chaperone of the glucocorticoid receptor in the pathogenesis and therapy of affective and anxiety disorders, Psychoneuroendocrinology 34 (Suppl. 1) (2009) S186-S195.

[9] E. Levy-Gigi, C. Szabó, O. Kelemen, S. Kéri, Association among clinical response, hippocampal volume, and FKBP5 gene expression in individuals with posttraumatic stress disorder receiving cognitive behavioral therapy, Biol. Psychiatry 74 (2013) 793-800

[10] M.E. Smith, Bilateral hippocampal volume reduction in adults with posttraumatic stress disorder: a meta-analysis of structural MRI studies, Hippocampus 15 (2005) 798-807.

[11] S. Kühn, J. Gallinat, Gray matter correlates of posttraumatic stress disorder: a quantitative meta-analysis, Biol. Psychiatry 73 (2013) 70-74.

[12] F.L. Woon, S. Sood, D.W. Hedges, Hippocampal volume deficits associated with exposure to psychological trauma and posttraumatic stress disorder in adults: a meta-analysis, Prog. Neuropsychopharmacol. Biol. Psychiatry 34 (2010) 1181-1188.

[13] M.B. First, R.L. Spitzer, M. Gibbon, J.B.W. Williams, Structured Clinical Interview for DSM-IV Axis I Disorders, Clinician Version (SCID-CV), American Psychiatric Press, Washington, DC, 1996.

[14] J.E. Hovens, I. Bramsen, H.M. van der Ploeg, I.E. Reuling, Test-retest reliability of the trauma and life events self-report inventory, Psychol. Rep. 87 (2000) $750-752$.

[15] D.D. Blake, F.W. Weathers, L.M. Nagy, D.G. Kaloupek, G. Klauminzer, D.S. Charney, T.M. Keane, A clinician rating scale for assessing current and lifetime PTSD: the CAPS-1, Behav. Ther. 13 (1990) 187-188.

[16] M. Hamilton, A rating scale for depression, J. Neurol. Neurosurg. Psychiatry 23 (1960) 56-62.

[17] I. Marks, K. Lovell, H. Noshirvani, M. Livanou, S. Thrasher, Treatment of posttraumatic stress disorder by exposure and/or cognitive restructuring: a controlled study, Arch. Gen. Psychiatry 55 (1998) 317-325.

[18] D. Perczel Forintos, Megáll az idő? Traumafeldolgozás kognitív pszichoterápiás módszerekkel, Pszichoterápia 20 (2011) 408-415 [Article in Hungarian].

[19] D. Wechsler, Wechsler Memory Scale-Revised, The Psychological Corporation, San Antonio, TX, 1981

[20] B.J. Sahakian, R.G. Morris, J.L. Evenden, A. Heald, R. Levy, M. Philpot, T.W. Robbins, A comparative study of visuospatial memory and learning in Alzheimer-type dementia and Parkinson's disease, Brain 111 (1988) 695-718.

[21] S. Kéri, Social influence on associative learning: double dissociation in high functioning autism, early stage behavioural variant frontotemporal dementia and Alzheimer's disease, Cortex, 54C, 2014, 200-209.

[22] C.R. Brewin, Episodic memory, perceptual memory, and their interaction: foundations for a theory of posttraumatic stress disorder, Psychol. Bull. 140 (2014) $69-97$ 
[23] H. Flor, F. Nees, Learning, memory and brain plasticity in posttraumatic stress disorder: context matters, Restor. Neurol. Neurosci. 32 (2014) 95-102.

[24] R.G. Parsons, K.J. Ressler, Implications of memory modulation for posttraumatic stress and fear disorders, Nat. Neurosci. 16 (2013) 146-153.

[25] K.W. Samuelson, Post-traumatic stress disorder and declarative memory functioning: a review, Dialogues Clin. Neurosci. 13 (2011) 346-351.

[26] D.T. Acheson, J.E. Gresack, V.B. Risbrough, Hippocampal dysfunction effects on context memory: possible etiology for posttraumatic stress disorder, Neuropharmacology 62 (2012) 674-685.

[27] S.H. Woodward, D.G. Kaloupek, L.J. Grande, W.K. Stegman, C.J. Kutter, L. Leskin, R. Prestel, M. Schaer, A.L. Reiss, S. Eliez, Hippocampal volume and declarative memory function in combat-related PTSD, J. Int. Neuropsychol. Soc. 15 (2009) 830-839.

[28] E. Levy-Gigi, S. Kéri, C.E. Myers, Z. Lencovsky, H. Sharvit-Benbaji, S.P. Orr, M.W. Gilbertson, R.J. Servatius, J.W. Tsao, M.A. Gluck, Individuals with posttraumatic stress disorder show a selective deficit in generalization of associative learning, Neuropsychology 26 (2012) 758-767.

[29] J.M. Pérez-Ortiz M.S. García-Gutiérrez, F Navarrete, S Giner, J. Manzanares, Gene and protein alterations of FKBP5 and glucocorticoid receptor in the amygdala of suicide victims, Psychoneuroendocrinology 38 (2013) $1251-1258$.
[30] R. Sapolsky, Stress, the Aging Brain and the Mechanisms of Neuron Death, MIT, Cambridge, MA, 1992.

[31] T. Frodl, V. O'Keane, How does the brain deal with cumulative stress? A review with focus on developmental stress. HPA axis function and hippocampal structure in humans, Neurobiol. Dis. 52 (2013) 24-37.

[32] T. Frodl, A. Carballedo, M.M. Hughes, K. Saleh, A. Fagan, N. Skokauskas, D.M. McLoughlin, J. Meaney, V. O'Keane, T.J. Connor, Reduced expression of glucocorticoid-inducible genes GILZ and SGK-1: high IL-6 levels are associated with reduced hippocampal volumes in major depressive disorder, Transl. Psychiatry 2 (2012) e88.

[33] M.G. White, R. Bogdan, P.M. Fisher, K.E. Muñoz, D.E. Williamson, A.R. Hariri, FKBP5 and emotional neglect interact to predict individual differences in amygdala reactivity, Genes Brain Behav. 11 (2012) 869-878.

[34] N. Fani, D. Gutman, E.B. Tone, L. Almli, K.B. Mercer, J. Davis, E. Glover, T. Jovanovic, B. Bradley, I.D. Dinov, A. Zamanyan, A.W. Toga, E.B. Binder, K.J Ressler, FKBP5 and attention bias for threat: associations with hippocampal function and shape, JAMA Psychiatry 70 (2013) 392-400.

[35] D. Pagliaccio, J.L. Luby, R. Bogdan, A. Agrawal, M.S. Gaffrey, A.C. Belden, K.N. Botteron, M.P. Harms, D.M. Barch, Stress-system genes and life stress predict cortisol levels and amygdala and hippocampal volumes in children. Neuropsychopharmacology, 39, 2014, 1245-1253. 